\title{
0 poder das palavras e das idéias: o caso do fundamentalismo islâmico
}

\section{RESUMO}

Este é um estudo sobre o debate teórico que se estabeleceu em torno da tese do choque civilizacional. Explora o argumento de que a cultura tem sido uma variável desconsiderada e desprezada no exame dos temas sociais e políticos contemporâneos. Explora também a temática do fundamentalismo islâmico desde a perspectiva cognitiva. Mostra as correntes teológicas e a crise interna ao Islã em torno da interpretação de suas fontes sagradas. Por fim, contempla a relevância política do papel que as idéias e a doutrinação têm na formação dos mapas mentais dos indivíduos, dos grupos humanos e das nações.

\section{PALAVRAS-CHAVE}

mapas mentais

fundamentalismo islâmico

cultura

\section{ABSTRACT}

This study reviews the large theoretical controversy around the clash of civilizations hypothesis. It presents and explores the renewed argument about the role which culture has in social and political themes. It makes use of cognitive insights to explore Islamic fundamentalism. It shows the internal fight in Islam among its school of thoughts around the ways human beings are allowed to interpret its religious sources. Finally it deals with the role performed by ideas in framing mental maps of individuals, groups and nations.

\section{KEY WORDS}

mental maps

islamic fundamentalism

culture

\section{Jacques Wainberg PUCRS}

A atual controvérsia internacional sobre a existência de um 'choque civilizacional' entre o ocidente e o oriente colocou em pauta o debate sobre o papel que as idéias e a doutrinação religiosa dos povos têm para as relações internacionais e interculturais. Ela tornou-se ainda mais intensa com a desconfiança manifestada por vários autores sobre a natureza da cultura islâmica acusada de ser a responsável pelo atraso econômico e cultural da ummah (os povos islâmicos), assim como pelo terrorismo fundamentalista contemporâneo. Segundo esta tradição de scholarship, crenças, valores e atitudes constituem a essência das culturas e são os elementos que em última instância geram o comportamento humano. Ou seja, elas constituiriam o DNA dos mapas mentais dos indivíduos e das nações. Tais fatores explicariam também porque, enfim, partindo de condições similares, uns e outros acabam desenvolvendo-se diferentemente.

O livro Culture Matters ${ }^{1}$ é um bom resumo desta renovada tradição investigativa que está no cerne deste debate. Seu pressuposto teórico básico afirma que quando tais fatores subjetivos (os valores, as crenças e as atitudes) se difundem no meio criam as bases de uma cultura. E ela, por sua vez, acaba influenciando a evolução política, social e econômica de uma sociedade. Entre seus precursores estão Aléxis de Tocqueville (que chamou a atenção para os valores da sociedade americana), Max Weber (que destacou a relação entre os valores do protestantismo e o desenvolvimento do capitalismo) e Emile Durkheim (que discutiu os problemas e os perigos dos valores da cultura contemporânea). Foi retomada e ampliada a partir dos anos 80 por uma nova geração de pensadores e pesquisadores, entre eles Lawrence E. Harrington. Este autor perguntou-se à época: por que poucos países pobres conseguiram obter altas taxas de desenvolvimento enquanto a vasta maioria, particularmente os localizados na África, América Latina e no mundo islâmico fracassaram? Gana e Coréia do Sul tinham dados econômicos similares em 1960, diz ele. Passados 30 anos, a Coréia do Sul tornou-se potência econômica respeitável. Gana não. Na sua visão, o que explica o sucesso de um e o fracasso de outro é o fato dos coreanos serem fiéis ao trabalho duro, valorizarem a educação, serem organizados e disciplinados, entre outros valores. ${ }^{2} \mathrm{O}$ cientista político Francis Fukuyama chama esta variável cultural de 'capital social'.

Ao referir-se à América Latina, em Underdevelopment is a state of mind - the Latin American Case, Lawrence Harrington tocou nesta tecla da subjetividade como 
fator decisivo e grave ao progresso. Referiu-se também aos casos de sucesso da Coréia do Sul, Costa Rica, Taiwan, Barbados, Hong Kong, Singapura, China, Índia, Irlanda, Espanha, Província do Quebec e Chile, entre outros. A prontidão ao empreendedorismo destes e de outros povos explicaria também porque programas de assistência funcionam melhor em certos países e pior noutros.

Tal interpretação afirma ainda que os países desenvolvidos beneficiaram-se de religiões e códigos de ética que alimentam a democracia e o desenvolvimento econômico. Seria o caso das seitas protestantes, do judaísmo e do confucionismo. Neles predominaria a idéia de que os indivíduos podem influenciar seus destinos. Decorre deste fato sua valorização à educação, ao trabalho e à celebração da realização e do mérito. Já nos casos do catolicismo, do Islã e da ortodoxia cristã do Oriente predominaria o fatalismo. As pessoas, por isso, estariam mais focadas no presente e no passado. No catolicismo, haveria mais hostilidade ao espírito competitivo do capitalismo e ao conceito de lucro e mais propensão à mensagem messiânica do socialismo. No caso específico do Islã, dá-se pouca prioridade à educação das mulheres, diz o autor. É ambivalente em relação ao valor do trabalho e da realização. E o status social deriva da família, do clã ou da classe e não do mérito pessoal.

Por fim, ao rediscutir as teorias de desenvolvimento, pergunta-se Harrison: por que afinal o mercado livre funciona bem na Índia e mal na América Latina?

\section{Valores e Mentalidade}

Este tipo de suspeita sobre o papel e o impacto da cultura no comportamento humano e social, e no desenvolvimento econômico dos povos, não é nova no Brasil. Fala-se no país e muito da mentalidade lusitana de seu povo, acusada de ser a causa 'secreta' de seu subdesenvolvimento. Esta indagação de porque afinal o Brasil, rico como é, não se tornou uma potência, é freqüente nos círculos acadêmicos, na opinião pública e na obra produzida na Escola Superior de Guerra. Samuel Huntington, autor de O Choque de Civilizações ${ }^{3}$, fez-se esta mesma pergunta: "A América seria a América de hoje se nos séculos XVII e XVIII ela tivesse sido povoada não por britânicos protestantes, mas por católicos franceses, espanhóis ou portugueses? A resposta é não. Não seria a América: seria talvez o Quebec, o México ou o Brasil," responde ele (com ironia). ${ }^{4}$

Tal questionamento é na verdade antigo e justifica a tradição de estudos comparados que há bom tempo se faz, por exemplo, entre o Brasil e os Estados Unidos. As respostas formuladas para o relativo fracasso de um e o sucesso de outro têm sido bastante diversificada, sendo esta, a do caráter nacional, pouco popular e pouco elaborada. A verdade é que há má vontade dos estudiosos com esta hipótese cultural. Relutam em considerar fatores psicológicos e 'espirituais' para explicar os problemas da nação. É mais freqüente outro tipo de argumentação, o que aponta obstáculos objetivos, mensuráveis e externos à 'alma nacional'.

Para os nossos fins cabe reafirmar que no fundo, esta temática, a do papel da cultura no condicionamento dos seres humanos e o impacto que valores, crenças e atitudes têm no desenvolvimento das nações, indivíduos e grupos, emerge, como afirmado, agora com vigor renovado devido à desconfiança de muitos no Ocidente com a cultura islâmica.

\section{A verdade é que neste mundo, como em muitos outros controlados por ortodoxias, sejam elas religiosas ou seculares, perdura a idéia de que são poucos os temas deixados ao livre arbítrio individual.}

A discussão é ampla e variada e no seu cerne estão várias dúvidas: seria esta teologia a causa do atraso no desenvolvimento dos países islâmicos? Haveria uma vocação 'nata' ao terrorismo na pregação corânica da jihad? Os valores de democracia, liberdade, igualdade civil e inovação tecnológica são incompatíveis aos valores e crenças destas sociedades tradicionais? Ou seja, haveria de fato um choque civilizacional como o proposto por Huntington?

Os alinhados a esta corrente culturalista têm afirmado a necessidade das sociedades islâmicas mudarem valores que os impedem ao progresso e ao desenvolvimento. É o caso de Bassam Tibi, por exemplo, que explica as dificuldades na democratização do Iraque devido ao fato de que as potências ocidentais invasoras não terem levado em conta a visão de mundo local. ${ }^{5}$ Não consideraram sua falta de motivação liberal impondo a força uma mudança de comportamento ainda imaturo na mente do Islã. Ele denomina de 'cultura defensiva' esta que os muçulmanos antepõem aos ocidentais e à modernidade. ${ }^{6}$ Pondera que quando eles se fazem esta pergunta, sobre o que não deu certo em seus próprios mundos, respondem usualmente que a causa do mal é o desvio da ummah aos preceitos do Islã. Esta é a resposta tradicional, introspectiva, ao contrário do que muitos no ocidente esperam. Para estes, os valores liberais são universais e deveriam fazer parte das ambições de todos que desejam realmente o progresso. Lamenta esta corrente de opinião culturalista (usualmente criticada por teóri- 
cos pós-coloniais como preconceituosa e racista) que a guinada muçulmana esteja ocorrendo para dentro, ao interior do universo mítico do Islã, e não para fora, rumo à ciência e à sociedade laica.

Outra fonte que dá guarida ao argumento culturalista e que realça sua importância para o mundo árabe e islâmico é o Arab Human Development Report 2002. Diz que sem democracia, direitos humanos ${ }^{7}$ e alfabetização ampla, desenvolvimento real não pode existir. E tais alterações só ocorrerão se houver modificação cultural que sustente estas transformações. ${ }^{8}$ Teólogos liberais do Islã têm divulgado ponto de vista similar. Afirmam que a doutrina islâmica foi seqüestrada e corrompida por um entendimento puritano que advoga sua proeminência sobre as demais correntes. Nos Estados Unidos um dos seus principais porta-vozes é Khaled Abou el Fadl. Seu livro, The Great Theft ${ }^{9}$, é um esforço para dissecar o fundamentalismo religioso. Diz que no Islã não há uma única fonte teológica válida, nem uma última instância, como é o caso do papado cristão. São muitas e divergentes as vozes a falar e a interpretar o legado do Alcorão. Por isso mesmo o cisma entre teólogos puritanos, como ele denomina a ortodoxia islâmica wahabita, e os liberais é profunda e indisfarçável. ${ }^{10}$

Ele igualmente se pergunta: é o Islã compatível com a democracia? O Islã possui um sistema político único? O califado deve ser restaurado? Qual o papel da shaaria (a lei islâmica) nos dias de hoje? Qual o papel dos juristas islâmicos na atualidade? Qual a relação entre o estado moderno e Deus? Qual o papel dos direitos humanos na civilização islâmica?

"Fiquei convencido de que o lado puritano esvazia o Islã de seu conteúdo moral e ético”, responde el Fadl. Sua crítica é profunda e voraz. Há uma crise de autoridade que chega ao caos (a maior parte das $f a-$ twas ${ }^{11}$ são promulgadas por indivíduos que não são estudiosos da tradição islâmica). E como há afirmações contraditórias nas fontes islâmicas não se sabe com certeza o que é legítimo e adequado. E ao contrário do passado, quando havia mais de uma centena de escolas teológicas ${ }^{12}$ que livremente debatiam este legado, sendo todas consideradas legais e legítimas, envolvendo juristas especializados na temática, hoje ao contrário, tais juristas perderam prestígio e o debate sufocado, as escolas nacionalizadas e controladas pelo aparato burocrático dos estados (como é caso da famosa Academia Islâmica Al-Azhar no Egito).

Por fim, o wahabismo ${ }^{13}$ se impôs em boa parcela do Islã, rejeitando a contribuição de outras escolas de pensamento e impondo os padrões de sua civilização beduína ao complexo mundo islâmico. Perdura agora sua visão etnocêntrica divulgada através do mundo com o apoio financeiro e logístico da Arábia Saudita que exporta este credo, impondo seus ditames como os únicos aceitáveis.

Khaled Abou el Fadl chama os puritanos tradicionalistas de 'farmacêuticos', pois "não sabem aplicar os métodos da lei à matéria prima, a considerar evidências contraditórias que competem entre si, a pesar os objetivos da lei e seus meios, a avaliar o interesse privado e o interesse público, a analisar as tensões entre regras e princípios, a fazer um balanço entre deferência, precedentes e demandas por mudança, a compreender as razões para as diferenças de opinião, e a estudar as demais considerações que são levadas em conta na produção de um julgamento legal". ${ }^{14}$

Farmacêuticos transmitem a tradição. Atuam sem saber diagnosticar doenças nem prescrever medicação adequada ao mal. Misturam suas preferências com a lei islâmica, corrompendo-a. E perpetuam atos de fanatismo que abalam a imagem do Islã. Estes livre-atiradores não são 'doutores', pois são ignorantes da jurisprudência e da metodologia. Um doutor precisa ser hábil nesta arte da relacionar as partes entre si.

\section{Esta temática dos mapas} mentais é importante não só para o entendimento dos processos cognitivos humanos em geral, mas também para se
avaliar as conseqüências
políticas dos padrões comportamentais dos povos.

Ou seja, critica o usual método conservador de exigir dos fiéis a memorização pura e simples do Alcorão, sem que se autorize ao mesmo saber como a fonte do material memorizado pode interagir com a metodologia legal a fim de produzir jurisprudência. ${ }^{15} \mathrm{~A}$ verdade é que neste mundo, como em muitos outros controlados por ortodoxias, sejam elas religiosas ou seculares, perdura a idéia de que são poucos os temas deixados ao livre arbítrio individual. O que está revelado não está disponível à discussão. Portanto, a 'contaminação' de seus hábitos, costumes, e crenças pela dúvida e a inquirição deve ser vigorosamente repelida.

\section{Debate Antigo}

Cabe realçar que este embate entre 'doutores' e 'farmacêuticos' não é novo no Islã. No medievo esta mesma tensão existia entre as escolas teológicas Mutazilite e Asharite. Tal confronto decorreu do rompimento intelectual de Wasil ibn Ata com o tradicionalismo de al-Hassan al-Basri - o que justifica o qualificativo a seus seguidores de Um'tazili - 'os que abandonaram'. Ou seja, o 'mutzalismo' desenvolveu-se na cida- 
de iraquiana de Basra, no início do século VIII, e preponderou no califado de Abbas (749-1258). Os pensadores tradicionalistas da escola Asharite - que afirmavam fé na interpretação literal do Alcorão e dos hadiths ${ }^{16}$ - tornaram-se seus opositores.

A teologia islâmica liberal "dos que abandonaram" visava aproximar o legado da revelação corânica ao racionalismo e à lógica grega mostrando que ambas as tradições eram compatíveis. Suas interpretações aos Cinco Pilares do Islã eram não convencionais e foram vistas como inaceitáveis aos olhos conservadores. Estes afirmaram em resposta que o ser humano não tem condições de compreender Deus e a razão é incapaz de discernir a moralidade. Entre os influentes teólogos desta corrente Asharite estava Al-Ghazali, também conhecido por seu nome latino Algazel, autor da obra de referência A Incoerência dos Filósofos na qual denuncia pensadores muçulmanos de seu tempo influenciados pela filosofia grega, entre eles $\mathrm{Al}$ Farabi e Abu-Ali Al-Husein ibn Abdullah ibn Sina Ibn Sina, conhecido também por Avicena. ${ }^{17}$

Para os fins desta reflexão, cabe realçar, portanto, que o foco da discórdia interna ao Islã estava - como ainda está - na polêmica sobre o direito dos indivíduos pensarem livre e criativamente sobre o legado da revelação (como queria o 'mutzalismo'). Aos olhos liberais contemporâneos, foram os Asharites que remeteram o Islã às trevas. Com o desejo de consolidar a fé puseram fim à filosofia e à especulação teórica (taqlid) no exato momento em que este espírito inquiridor islâmico se expandia e se diversificava no período do século XII ao XIV.

\section{Idéias messiânicas}

Segundo esta tradição teórica culturalista, e como exposto, esta temática dos mapas mentais é importante não só para o entendimento dos processos cognitivos humanos em geral, mas também para se avaliar as conseqüências políticas dos padrões comportamentais dos povos. Por exemplo, as idéias messiânicas tinham (como ainda têm e provavelmente sempre terão) esta rara capacidade de domínio do imaginário e da pulsão existencial de boa parcela dos indivíduos. As ideologias seculares focaram e continuam a focar o pensamento na imaginação, no desconhecido a ser conquistado e elaborado pelo ser humano no futuro. Este labor político cheio de esperança tem se disfarçado ao longo da história de sonho e promessa. A utopia destas pregações está sempre à espera de uma nova arquitetura social e do surgimento de um novo homem.

$\mathrm{Na}$ obra teológica conservadora, ao contrário, a utopia está no passado, distante e inacessível. Por isso, cabe ao labor humano descobrir a verdade promulgada e seguir a norma prescrita na revelação. É esta disciplina cega ao dito e repetido desde o alvorecer da fé que deve comprometer os que desejam apressar de alguma forma o reino de Deus na Terra. Como as ideologias revolucionárias, também estas teologias tornam-se com o tempo prescritivas e normativas. Tornam-se 'iteologias'. E a missão da obra exegética que visa decifrar a mensagem divina revelada tornase ao fim igualmente política. Mobilizados pela expectativa da salvação, seus porta-vozes e sábios, os 'iteólogos', popularizam o que entendem ser os ditames da tradição, impõem dogmas, ritualizam a rotina, vigiam o comportamento, e se envolvem ou aspiram se envolver com os temas mundanos de Estado.

\section{A força de bin Laden, diz ele, não se origina de sua prédica religiosa, mas política.}

Cabe realçar que esta acusação, de que há algo de errado na cultura islâmica ${ }^{18}$ e que são tais fatores 'espirituais' os responsáveis pela violência religiosa terrorista e pelo estado de decadência econômica e cultural dos estados muçulmanos, não é consenso e provoca reações. Mahmood Mamdani, em Good Muslim, Bad Muslim, a political perspective on culture and terrorism, diz que Huntigton diabolizou o Islã todo. ${ }^{19}$ Em resposta propõe a idéia de que existam igualmente 'bons ocidentais' e 'maus ocidentais'. Ele questiona o pressuposto culturalista, o de ver a ação política islamita radical como um efeito da civilização islâmica. Isso nos obrigaria a ver também a ação imperial ocidental como resultado da cultura ocidental. Em suma, deseja descartar 'a conversa mole do culturalismo. ${ }^{20}$ Diz que esta corrente de pensamento evita a história e problemas concretos e tende a estimular punições coletivas. Iguala o terrorismo ao islamismo, justifica a guerra contra um país inteiro (o Iraque e o Afeganistão), ignora a história recente, desconsidera o contexto, torna os povos islâmicos inertes como se fossem peças de museus incapazes de ação e iniciativa e exige que se distingam bons muçulmanos de maus muçulmanos.

Pondera que o Islã, como o cristianismo e o judaísmo, não é monolítico e que o estereótipo apresentado exclui os debates, as controvérsias e as tensões internas ao Islã. Afirma, por isso, que o choque cultural e ideológico é interno a cada civilização e não entre as civilizações. Lembra que Ronald Reagan, a seu tempo, convidou os lideres dos Mujahideen ${ }^{21}$ à Casa Branca, e porque lutavam contra os soviéticos comunistas afirmou sem pestanejar que "eram os equivalentes aos Pais Fundadores dos Estados Unidos." A acusação do autor vai mais longe: os Estados Unidos incentivaram o desenvolvimento fundamentalista islâmico, e através dos paquistaneses ajudaram a recrutar e treinar milhares de voluntários islâmicos para a luta contra os russos, estimularam as madrassas a tornarem-se escolas de doutrinação jihadista, recrutaram 
bin Laden, formaram uma brigada internacional sob seu comando - conhecidos como afegãos-árabes pagando a cada militante 1500 dólares mensais, o que acabaria provocando igualmente o aumento na produção afegã de heroína, país que passou a fornecer $60 \%$ da droga ao próprio mercado dos Estados Unidos. $^{22}$

\section{Oeste também é relacionado com uma cultura, a estabelecida pelo cristianismo e pelo pensamento grego.}

Ou seja, o mundo islâmico não tinha tido a experiência de uma revolta jihadista armada por séculos. Ela ressurgiu com o apoio e a iniciativa da mão invisível dos Estados Unidos. E isso não tem nada a ver com a cultura islâmica. O fundamentalismo islâmico é por isso mesmo subproduto da guerra fria, é um fenômeno moderno, sendo os talibãs os sobreviventes brutalizados da guerra contra os soviéticos. ${ }^{23} \mathrm{~A}$ força de bin Laden, diz ele, não se origina de sua prédica religiosa, mas política. E no que se refere ao Oriente Médio, diz ele, os Estados Unidos lutam na verdade é por óleo barato e não por liberdade de expressão. ${ }^{24}$

\section{Estudos Empíricos}

Mobilizados pela dúvida e pelo confronto, estudos empíricos têm sido feitos para testar a validade deste pressuposto teórico combalido por Mahmood Mamdani. Os dados coletados sobre os valores humanos no projeto World Values Survey, que investigou 78 sociedades, correspondendo a $80 \%$ da população mundial em três períodos distintos de pesquisa é hoje o principal banco de dados para pesquisadores interessados em responder estas perguntas e outras similares.

Por exemplo, Ronadl Inglehart e Wayne E. Baker, em Modernization, cultural change, and the persistance of traditional values, afirmam que o desenvolvimento econômico está diretamente ligado a mudanças em valores sociais. Tal mudança exige que a sociedade se torne menos rígida, mais tolerante e racional, confiante e participativa. Isso não significa que traços culturais distintivos dos povos desapareçam. Tais marcas são registros que perduram no tempo. É o caso do Japão e de outros países asiáticos que superaram os índices de crescimento e modernização de muitos estados do ocidente, sem que isso significasse uma perda ou mácula de suas características culturais originais. Decorre desta conclusão que é um equívoco a reação fóbica e nativista de muitos à globalização por temor à homogeneização, americanização e secularização. As civilizações persistem apesar do impac- to de tais inovações nos hábitos e costumes locais. Afinal, cada país persegue o desenvolvimento desde suas próprias condições e características. Além disso, modernização é um fenômeno probabilístico, não determinístico. Ou seja, tende a modificar uma sociedade numa certa direção prevista, mas tal rumo não é inevitável.

Na verdade, há nações 'congeladas' que evitam a ocidentalização sem se modernizar. O regime kemalista da Turquia fez o oposto: se ocidentalizou e se modernizou em certa medida. Algumas outras nações do Islã se modernizaram sem se ocidentalizar (é o caso das nações do Golfo). Já o caso do Egito é o contrário: se ocidentalizou sem se modernizar. Há também países em ziguezague: se ocidentalizaram mais que se modernizaram recuando a seguir para um menor padrão de ocidentalização e com ritmo maior de modernização numa espécie de arrependimento e fruto de uma crise de identidade. Ou seja, o Islã revela-se relativamente perplexo sobre como compatibilizar a tradição herdada com as tendências culturais e tecnológicas contemporâneas e que se espalham através do mundo devido aos contatos intensos entre os povos, a educação e a comunicação internacional.

Os intérpretes dos dados apresentados em World Values Survey ${ }^{25}$ dizem que é possível posicionar os grupos humanos em dois grandes blocos, o constituído por valores nos eixos (1) Sociedades Tradicionais/ Seculares-Racionais e (2) Sociedades Sobreviventes/ Auto-expressivas. No primeiro caso, a do eixo Tradição-Secularismo, percebe-se a tensão existente entre sociedades nas quais a religião é um fator grave e central e nas demais onde ela exerce um papel menor. Grupos humanos posicionados próximos ao pólo tradicional enfatizam a importância da relação entre pais e filhos, o respeito à autoridade e a padrões tradicionais estritos, e a rejeição do divórcio, do aborto, da eutanásia e do suicídio. Estas sociedades apresentam altos níveis de orgulho nacional. As posicionadas mais próximas do pólo secular-racional têm valores e preferências opostas a estas.

O segundo eixo revela a mudança nos valores das sociedades que estão vivendo a transição do estágio industrial ao pós-industrial. Isso provoca a polarização entre valores que já não são mais os relacionados à pura busca da sobrevivência física das pessoas. Há agora espaço a outros desejos e necessidades que permitem a expressão de sentimentos e sensibilidades variadas como melhor qualidade de vida, apoio ao ambientalismo, tolerância à diversidade étnica, religiosa e sexual, desejo de participar da vida comunitária e dos processos de decisão da vida política econômica e social, aumento na confiança mútua entre os indivíduos, adoção de posições políticas moderadas, respeito à liberdade individual além de outros valores subjetivos relevantes considerados decisivos para a consolidação da democracia. 
Há evidências de que em quase todos os países desenvolvidos houve uma mudança de valores desde o pólo Tradicional ao Secular-Racional. Na próxima fase, quando se tornam 'sociedades do conhecimento', no estágio pós-industrial, migram desde o pólo nos quais os valores de Sobrevivência dão lugar crescentemente aos de Auto-Expressão.

\section{As Maneiras de Pensar}

Atualmente, outras metáforas têm sido utilizadas para explorar aquelas duas maneiras de pensar. Diz-se, por exemplo, que 'cartografar' e 'empilhar' são duas estratégias muito distintas de refletir. 'Empilhar' dados e informações significa reforçar a norma social, manter o mundo no rumo, determinar normas e procedimentos e produzir o senso comum. É a estratégia conservadora. 'Cartografar', por sua vez, é fazer política a maior parte do tempo, intervindo no destino do universo. É a estratégia liberal.

Os dois, 'empilhadores' e 'cartógrafos' convivem com dificuldade. Cartógrafos pensam nos 'empilhadores' como ignorantes e acomodados. Estes, por sua vez, rotulam os primeiros como agitados, pois desejam mudar tudo aos poucos a maior parte do tempo. $\mathrm{O}$ que os diferencia no fundo é que os 'cartógrafos' têm um mapa mental em expansão, o 'empilhador' em sofreguidão.

Há também a crítica inversa e 'orientalista' ao mapa mental - ideológico - dos ocidentais sobre o Islã e outros povos. Diz esta corrente de pensamento que se desenvolveu a partir da obra 'Orientalismo' de Edward Said ${ }^{26}$, que os mapas de papel refletem em boa medida preconceitos ideológicos e revelam falta de rigor conceitual. Por exemplo, o redesenho do mapa da Europa após o colapso da União Soviética e a inclusão de antigos países do bloco comunista na esfera capitalista e democrática ocidental e à Comunidade Européia, produziu alteração profunda nas imagens que temos destes povos que antes viviam na esfera de influência comunista de Moscou. Curiosa era também a incerteza que pairava em 2005 sobre a entrada da Turquia na mesma Comunidade Européia.

Geograficamente imóvel, mas mentalmente movediça e incerta, este país vagava, no início do século XXI, perdida e sem rumo na cabeça de todos, incluindo as cabeças turcas, já que não poucas vozes advogam sua vocação islâmica e incompatibilidade à Europa cristã.

A própria idéia de Ocidente é ambígua. Por vezes, fica restrita às Américas e à Europa Ocidental (incluindo a Grécia). Caso ampliado, o conceito pode incluir ainda a Austrália, a Nova Zelândia e Israel. Já países como o Japão, a Coréia do Sul e Taiwan são consideradas ocidentais em certas circunstâncias. A China continental, o Oriente Médio e a Índia geralmente são excluídas. Já a Rússia, após a queda do comunismo, balança entre um mundo e o outro. Não há que confundir o Primeiro Mundo com o Ocidente, já que a América do Sul pobre é ocidental. Mesmo assim, predomina a imagem de que uma coisa equivale à outra. O termo Norte com freqüência toma o seu lugar. Outras vezes, os 30 países da Organização para o Desenvolvimento e Cooperação Econômica (e que inclui os países da Comunidade Européia, Noruega, Islândia, Suíça, Canadá, Estados Unidos, México, Austrália, Nova Zelândia, Turquia, Coréia do Sul e Japão) são chamados de Primeiro Mundo, ou Mundo Desenvolvido, muito embora o México e a Turquia, que fazem parte da organização, sejam ainda subdesenvolvidos.

O Oeste também é relacionado com uma cultura, a estabelecida pelo cristianismo e pelo pensamento grego. Também se diz que o Ocidente possui valores próprios e que os mesmos são superiores e por isso devem prevalecer no mundo todo (é a opinião do filósofo Francis Fukuyama, por exemplo.) Entre eles estão a liberdade, a democracia e os direitos humanos. Valores que recusam o totalitarismo, muito embora esta concepção de regime político tenha sido aplicado no ocidente. Da mesma forma, a escravidão, embora não tenha sido exclusividade ocidental, alcançou proporções massivas em vários países do oeste que hoje são paladinos da igualdade social. Já a rebeldia fundamentalista contra a ocidentalização da ummah decorre de visão de que o mundo secular do ocidente é moralmente decadente e que sua 'investida' sobre a mente dos povos árabes e outros da Ásia, África e Extremo Oriente equivale ao conceito de colonização.

\section{Também a idéia de Europa Central foi imagem construída. Ela se alteraria profundamente após a queda do muro de Berlim, em 1989.}

Também o conceito de Oriente é ambíguo e vago. Literalmente significa o nascimento do sol e deriva da palavra latina oriens. Era usado para significar o leste. Na França os termos equivalentes são Levante e Anatólia, do grego anatole, igualmente a posição em que o sol nasce. Aos olhos de Larry Wolff, autor de Inventing Eastern Europe: The map of Civilization on the mind of the Enlightenment ${ }^{27}$, a construção da imagem da Europa Oriental como entidade separada da Ocidental 'civilizada' resultou da estereotipia da região produzida nas obras de autores iluministas (em especial, Voltaire e Rousseau), que a descreveram como homogênea e bárbara. Ele mostra a forma como os ocidentais 'consumiram' o leste europeu. 
Por vezes suas terras 'perdidas`ora eram incluídas ora excluídas da cartografia 'civilizada' dos povos 'nobres`. A fronteira mental entre aquela respeitável Europa e a que lhe estava a leste, na 'barbárie', dependia assim destas linhas tortuosas e vagas que se evaporavam e ressurgiam por fatores variados e que expressavam ora o gosto ora o desgosto de uns em relação aos outros.

\section{Dizem que a democracia é a estrutura sobre a qual está montado o pensamento capitalista. Irritam-se em especial com sua pretensão que faz crer aos indivíduos que o Legislador é humano e não 0 Todo Poderoso.}

À época do Iluminismo as fontes documentais que autorizavam o observador monitorar tal mapa simbólico ocidental eram mais limitados. Os diários de viagens, a ficção literária e a arte eram algumas delas. $\mathrm{O}$ observado era mantido à distância, sem voz. Os iluministas costumavam catalogar os traços étnicos e físicos das populações de certa área (o que se chamaria hoje de estudos etnográficos, antropológicos e de folclore) localizando-os num eixo em cujos extremos estavam o barbarismo (Ásia) e a civilização (Europa). E ao inventarem o eslavo da Europa Central inventaram a si próprios por contraste.

Com as interações modernas facilitadas há cada vez mais a rebeldia do nativo contra a simplificação e o empobrecimento de sua imagem produzida e divulgada além-fronteira, como é o caso agora nesta discussão sobre 'a mente islâmica'. Além disso, há pouca clareza sobre os fixadores das essências afirmadas e imaginadas. As identidades tornam-se por decorrência um barril de pólvora e motivo de disputas políticas. Nesta mesma tradição, Maria Todorova escreveu Imagining the Balkans ${ }^{28}$, além de outros autores $^{29}$, que decifraram este tema das imagens fabricadas e que revela o papel e a relevância do imaginário social nas relações internacionais e interculturais.

Também a idéia de Europa Central foi imagem construída. Ela se alteraria profundamente após a queda do muro de Berlim, em 1989. Na verdade, após o choque político e mental provocado em todo o mundo com o débacle do comunismo, os novos mapas da Europa e a literatura popular começaram a registrar com mais intensidade o novo construto da Europa
Central como entidade autônoma, como mostra Katarzyna Murawska-Muthesius. ${ }^{30}$

Como antecipado, nesta luta em torno dos mapas de papel e os mentais, uma das últimas e polêmicas cartografias do mundo foi a elaborada por Samuel Huntington. Sua tese é a de que o mundo é composto por várias civilizações, e que os conflitos internacionais derivam do choque entre elas. Os países católicos e protestantes da Europa Central e Ocidental, junto com os Estados Unidos, Canadá, Austrália e Nova Zelândia, por partilharem valores comuns, constituiriam a civilização Euro-Atlântica. Alianças entre esta civilização e outras seria possível desde que os aliados tivessem assimilado alguns dos valores centrais dos euro-atlânticos.

\section{O Mapa Mental Fundamentalista}

Este tema dos conceitos e preconceitos é grave, pois o que autoriza o assassinato do outro é a imagem decaída que temos de sua cultura, história, religião, hábitos e costumes. É um álibi útil aos fins do martírio político e da absolvição celeste e humana. Mapas mentais fazem parte do arsenal das disputas comerciais, dos encontros e desencontros interculturais e principalmente da guerra psicológica. Como insinuado, amaldiçoar o outro numa incessante ruminação desumanizadora é contaminar as novas gerações com os rancores da velha eternizando a guerra. Mapas mentais podem matar, como se sabe com os diversos genocídios da história.

Na sua elaboração, o melhor que as pessoas poderiam fazer para aprender e conhecer seria experimentar. Colocar-se na posição de explorador da vida para assim produzir com autonomia imagens do mundo sobre as quais teriam responsabilidade pessoal. Mas sabemos que não é isso o que ocorre com grande parcela destas pistas fincadas em nosso espírito. A educação e a doutrinação cultural, política e religiosa nos acolhem e nos acondicionam antes mesmo de podermos dizer sim e não. O contágio social é inevitável. E até que possamos com dor e sofrimento nos rebelar contra uma e outra dessas rotas cerebrais, eventualmente defeituosas, vive-se as conseqüências de seus efeitos corrosivos. Por outro lado, o conformismo nos promete conforto e abala na maior parte dos casos este espírito inovador de expedicionário das idéias.

Ou seja, e como já sugerido, a tradição é forte e poderosa e as imagens que nos chegam por seu intermédio são mais facilmente digeridas do que a descoberta original, pessoal, sempre mais dolorosa e arriscada. Mapas mentais herdados sobrepõem-se em número e força às imagens construídas do mundo pela subjetividade. De resto, ir a campo, ver e observar nem sempre é possível. Por vezes, e com freqüência, prefere-se a ilusão à realidade, o mapa ao território. $\mathrm{O}$ teste de veracidade que o lúdico proporciona agrada a poucos, os vocacionados à descoberta, e que reve- 
lam coragem para contrariar o dito e o repetido como senso comum.

As imagens mentais resultam destas informações coletadas, preservadas e relacionadas que nos ajudam a construir sentido e o significado das ocorrências cotidianas. Nas novas situações lembramo-nos das imagens arquivadas das velhas experiências. Por vezes, o novo se choca com o velho, causando sofrimento e dor. Noutras vezes, imagens depositadas na mente se disfarçam de sagradas. Nesta embalagem, são mais facilmente acolhidas e respeitadas. É assim que os mortos comandam a vida dos vivos. Num ato de rebelião os vivos que vivem são obrigados a gritar por vezes um basta. Deixar os mortos em paz para que a paz seja concedida aos que lhes sobrevivem, especialmente naquelas situações em que a ruminação histórica deseja fazer perdurar o rancor e a revanche. Lembrar por vezes faz mal. Na busca da paz deve-se controlar este poder que as imagens do passado possuem.

Este tipo de formulação, desde os fundamentos da cognição, é uma das formas possíveis de explicar a crise política contemporânea em torno da tese do choque civilizacional. Aos olhos puritanos haveria de fato um embate frontal de idéias, entre o movediço e instável capitalismo e liberalismo com as verdades eternas do Islamismo. E somente no Islã, dizem eles, é que o capitalismo enfrenta agora realmente dura e persistente resistência.

Para estes, para a ortodoxia islâmica wahabita, herdeira da tradição Asharite, haveria uma campanha ocidental em andamento pela secularização do Islã e por sua destruição. Em reação, esforçam-se em 'desmascarar os slogans do mundo capitalista e liberal' que lhe fazem concorrência na conquista do imaginário da ummah. Dizem que a democracia é a estrutura sobre a qual está montado o pensamento capitalista. Irritam-se em especial com sua pretensão que faz crer aos indivíduos que o Legislador é humano e não o Todo Poderoso. Para os muçulmanos adotarem a democracia significaria desacreditar todas as determinações aos quais os versos corânicos obrigam obediência. Pluralismo também seria uma falácia. O Islã tem sua própria multiplicidade desde que os grupos tenham idéias islâmicas e que não visem solapar sua existência. A crença nos direitos humanos é vista como imposição ocidental, que não tem base na tradição islâmica e que, por isso mesmo, deve ser também repelida. A liberdade de crença é válida somente aos não muçulmanos. Para estes, a regra é outra: "após abraçar o Islã eles não têm a opção de descrer e renunciar".

Nesta tentativa de desconstrução das bases ideológicas da sociedade liberal argumentam ainda que é pressuposto da liberdade de expressão o direito de negar e proclamar abertamente descrença na existência de Alá. E isso é inadmissível. Como inadmissível é a pretensão de evocar qualquer idéia que contradiga o credo islâmico ou que discorde das regras que dele emanem. "Liberdade de expressão para os capitalistas não está simplesmente confinada à transparência dos dirigentes, ou nas críticas aos políticos e outros, mas também inclui a liberdade de proclamar livremente a heresia, negar a existência de Alá, apelar para qualquer idéia que contradiga o credo islâmico ou que discorde com suas regras, como a promoção daquilo que Alá proibiu como é o caso da usura, o jogo, o álcool, a fornicação e a perversão sexual, e de muitas idéias que solapam os valores islâmicos...". ${ }^{31}$

Dizem que a liberdade de expressão permite aos 'hipócritas' que desobedecem a Alá realizar sua campanha contra Ele para destruir a ummah, fragmentado-a em grupos étnicos, regiões, seitas e grupos. "Basta lembrar como tal liberdade permitiu ao apóstata Salman Rushdie proclamar abertamente e distribuir o que disse sobre o Profeta e às mães dos crentes para dar-se conta da extensão que esta liberdade alcançou para os capitalistas." Os muçulmanos podem dizer o que bem entendem, desde que nos limites do credo islâmico.

Recusam igualmente a liberdade de propriedade que causa males que contaminaram profundamente os seres humanos como a imoralidade, o crime organizado, o egoísmo, etc. Por decorrência lógica, opõemse à visão liberal de livre mercado "que a América e o Ocidente em geral advogam." Tal visão permitiria ainda que hereges tomem o controle de suas economias. O capitalismo é culpado igualmente de uma excessiva liberdade individual que autoriza homens e mulheres coabitarem sem qualquer legalidade, a homossexualidade, a perversão sexual e a pornografia.

\section{Ver para crer é exercício da razão que demanda outra formatação e disposição afetiva: curiosidade, inquirição e dedução.}

Decorre daí a visão que está proibida a um muçulmano a liberdade individual porque tal atitude permitiria o que Alá proíbe. "Liberdade individual é a liberdade da fornicação, perversão sexual, imoralidade, alcoolismo e outras doenças."

\section{Considerações finais}

Como exposto, frente a este agora renascido mapa mental asharite puritano, de 'farmacêuticos' e empilhadores', ergueu-se no seio da ummah outro, liberal, marginal, mutazilite, em boa medida reprimido nos desertos da Arábia, perseguido e por isso diaspórico, de 'doutores e cartógrafos'. Correntes ideológicas ou 
'iteológicas' acabam, inevitavelmente, sempre fraturadas, como se sabe da história das idéias. Ocorreu no cristianismo, e no judaísmo, e no marxismo e no liberalismo igualmente. No caso, a gravidade desta cisão teológica é a conseqüência militante e militar deste tipo de fundamentalismo religioso, razoavelmente (mas não plenamente) contido noutras tradições no momento.

\section{0 labor de demolir paradigmas e construir nova e mais adequada imagem do mundo é cansativo, pois exige sempre que se chegue a lugares antes nunca visitados.}

Por isso mesmo, este debate de idéias e esta obra intelectual sobre o sentido e o significado da missão islâmica no mundo interessa agora a todos. Tornouse um tema que têm conseqüências não só religiosas e éticas, mas geopolíticas. O que explica porque a radicalidade desta visão fundamentalista não passa despercebida. Seu grito em favor do choque civilizacional é insuspeito. Tal fervor teve como conseqüência mais deletéria o azedume do diálogo intercultural e, como dito, o mal-estar crescente em relação a seus fundamentos filosóficos indisponíveis aos valores da modernidade democrática, como entendido e percebido nas sociedades liberais. Por isso mesmo, é grande a torcida no ocidente pela reforma 'protestante' do Islã e a emergência no seio da ummah igualmente de um 'ecumenismo'. No primeiro caso, aliviaria o temor já referido. Poria a pique o argumento de que o deu errado no Islã é o Islã propriamente dito, no espírito da fala emocional proferida por Oriana Fallaci, em seu manifesto 'A Raiva e o Orgulho.' ${ }^{32}$ No segundo caso, evitaria os choques internos na própria sociedade muçulmana, como mostra o caso da guerra civil entre xiitas e sunitas no Iraque.

Se as imagens mentais produzidas pela pregação e doutrinação não fossem tão relevantes, o que estes personagens da Arábia dizem sobre hereges e infiéis, sobre o Califado e os desejos de Alá, seria muito provavelmente tópico marginal de interesse dos que observam (quando observam) à distância as ocorrências e a obra cultural daquela parte do mundo. Mas sabemos todos que as imagens mentais produzidas por tais e outros discursos similares não são fúteis, pois governam em boa medida e nas condições adequadas a ação humana. Os indivíduos reagem levando em conta o que sabem, e o que eles sabem, na maioria dos casos, deriva das mensagens que lhes chegam e to- cam o espírito, alterando, reforçando e formando o repertório de imagens ${ }^{33}$ que ficam depositadas em suas cabeças aguardando os estímulos que os põem em movimento e que geram por fim as atitudes.

Nas disputas ideológicas e 'iteológicas', certo tipo de pessoa crê antes de ver. Como ocorre no caso fundamentalista, predomina nestes ambientes a fé cega. No campo grave da emoção reina em tal mente condicionada fortemente pela tradição a estereotipia que enquadra o novo nos padrões do velho, do conhecido e estimado, superestimado.

Ver para crer é exercício da razão que demanda outra formatação e disposição afetiva: curiosidade, inquirição e dedução, um pensamento mais rigoroso, lógico e menos disponível à exaltação e mais disposto à inquietação. Este tipo de pensamento sempre testa a teoria que lhe chega aos ouvidos visando com isso aperfeiçoar os mapas cognitivos que norteiam a jornada das pessoas nos territórios da vida. O labor de demolir paradigmas e construir nova e mais adequada imagem do mundo é cansativo, pois exige sempre que se chegue a lugares antes nunca visitados. E cartógrafos e doutores com esta vocação geralmente convivem mal com as imposições derivadas da tradição. afAMEcos

NOTAS

1. Harrison, Lawrence E. \& Huntington, Samuel P. Culture Matters. Basic Books. New York, 2000. Ver também Harrison, Lawrence E. \& Kagan, Jerome. Developing Cultures. Essays on Cultural Change. Routledge. 2006; Harrison Lawrence E. The Central Liberal Truth. Oxford University Press, 2006

2. Culture Matters, p.1

3. Samuel P. Huntington. O choque de Civilizações. Ed. Objetiva, RJ.1996

4. Kip Keller. “Divided we stall? Samuel Huntigton goes from the clash of civilizations to the clash of American civilization." The Austin AmericanStatesman. 30 de maio de 2004, pK5

5. Culture Change in Islamic Civilization, in Culture Matters, p.245

6. Ibid, p.246

7. Este debate sobre direitos humanos e o Islã é intenso na revista Human Rights Quarterly. Ver por exemplo: Heiner Bielefeldt. Muslim Voices in the Human Rights Debate. 17:4(1995)p.587; Abdul Aziz Said. Precept and Practice of Human Rights in Islam. 1:1(1979: Jan/Mar):p.63

8. Ibid, p.256 
9. The Great Theft. Harper, San Francisco. 2005

10. Ibid.p.13

11. Éditos legais.

12. The Great Theft, p.149

13. Este termo tem sido utilizado de forma pejorativa pelos oponentes desta escola teológica sunita seguidora dos ensinamentos de Muhammad ibn Adb al Wahhab (1793-1792). Outro termo utilizado para descrever estes piedosos do Islã é 'sala$\mathrm{fi}^{\prime}$, muito embora ele seja utilizado também por fiéis que não seguem de $\mathrm{Al}$ Wahhab.

14. The Great Theft, p.90

15. ibid

16. Costume derivado dos ensinamentos do Profeta e seus seguidores.

17. Provocado por sua interpretação literal, outro teólogo, Ibn Rushd (Averroes), filósofo árabe que viveu na Espanha (1126-1198), escreveria a Incoerência da Incoerência (Tahafut-al-Tahafut), muito embora não tenha obtido o mesmo sucesso de seu opositor. Trabalhou como advogado e médico em Córdoba. Viveu certo tempo no Marrocos como refugiado devido à repercussão de sua obra rotulada nos círculos islâmicos da época como herética. Sua influência permaneceu forte até à Renascença. Tentou separar os domínios da fé e da razão, afirmando que não precisam se reconciliar porque não conflitam. Declarou sua simpatia pela filosofia como a forma mais elevada de inquirição. Desagradou também a Igreja católica por suas idéias sobre imortalidade e a eternidade da matéria.

18. Um dos autores que liderou este debate é Bernard Lewis autor da obra "What went wrong? The clash between Islam and modernity in the Middle East.Harper Perennial. 2003

19. In Eric Hershberg \& Kevin W. Moore (eds). Critical Views of September 11. Social Science Research Council. 2002, NY

20. In Eric Hershberg \& Kevin W. Moore (eds). Critical Views of September 11. Social Science Research Council. 2002, NY, pg. 45

21. Os militantes islâmicos que lutam a jihad, a Guerra santa.

22. Ver Rachid, Ahmad. “The Taliban: exporting extremism". Foreign Affairs, November-December, 1999.

23. p.57

24. p.57

25. Ver www.worldvaluesurvey.org

26. Orientalismo - O oriente como invenção do ocidente. Cia. Das Letras. 2001

27. Stanford, Cal.: Stanford University Press, 1994.

28. Oxford University Press, 1997.

29. Vesna Goldswrorthy. Inventing Ruritania: The Imperialism of the Imagination. New Haven: Yale , 1998; Stephen R. Graubar. Eastern Europe... Central Europe... Europe. Boulder, CO: Westview Press, 1991; William H. McNeill. “ What we mean by the west.", Orbis 41.4(1997):513-24.

30. Ver Distinguishing white from white: Images of East Central European Difference after the Fall of Wall.

31. The American Campaign to Supress Islam. Hizb-ut Tahrir. Al-Khilafah Publications. 25 de março de 1996. p. 27

32. Difel. 2002 (edição portuguesa)

33. Ver Kenneth Boulding, The Image. Ann Arbor, University of Michigan Press, 1956. 